\title{
Cross Ventilation in High-Rise Apartment Building: Effect of Ventilation Shaft Aperture Configuration on Air Velocity and Air Flow Distribution
}

\author{
M. Rizal Fahmi ${ }^{1}$, Ima Defiana ${ }^{1}$, I Gusti Ngurah Antaryama ${ }^{1}$
}

\begin{abstract}
Ventilation shaft can be used in apartment units to provide cross ventilation by creating a pressure difference between the room's windward opening and outlet at the roof. The previous research about ventilation shaft has shown its potential in providing good natural ventilation in high-rise apartment building. This paper examines the influence of ventilation shaft aperture configuration on its ability to generate air movement and uniform flow distribution. The experiment is carried out using computational fluid dynamics with RNG k-e calculation method. Ventilation shaft system with a uniform aperture can produce very high air velocity only at the top floor while ventilation shaft system with internal aperture size increased from the upper floor to the lower floor can produce better air flow distribution.
\end{abstract}

Keywords-Apartment, Cross Ventilation, High-Rise, Tropical, Ventilation Shaft.

\section{INTRODUCTION}

A ventilation shaft connected to a single room in a highrise apartment building has been previously investigated by [1]. The results show that the ventilation shaft can increase average air velocity in the test room compared to the room with a single sided ventilation. The ventilation shaft has a similar mechanism with the cross ventilation where there is a pressure difference between inlet and outlet openings so that the air can move through the room. A room which only has a single side connected to the outside environment can have the similar pressure difference by placing a shaft which connects the room with an outlet at the rooftop. The positive wind pressure at the inlet area and negative pressure around the outlet area at rooftop can result in pressure difference which forces the air to flow through the room.

In order to increase the ventilation shaft's efficiency in space usage and functionality, it can also be connected to multiple rooms arranged vertically. Unfortunately, ventilation shaft system with multiple rooms connected to it has a major problem which is non-uniformity of air flow distribution on each room. If the opening which connects

${ }^{1}$ M. Rizal Fahmi, Ima Defiana, I. Gusti Ngurah Antaryama are with Department of Architecture, Faculty of Architecture, Design, and Planning, Institut Teknologi Sepuluh Nopember (ITS), Kampus ITS Sukolilo, Surabaya 60111, Indonesia. E-mail: rizal14@mhs.arch.its.ac.id; may.d@arch.its.ac.id; antaryama@arch.its.ac.id. each room to the shaft has the same size, the air flow tends to concentrate on the nearest room to the system's outlet at the roof. The room at the highest floor, which is nearest to the roof, experiences the highest air velocity and air flow rate while rooms at the lower floors experience lower air velocity and air flow rate.

A ventilation shaft system connected to multiple rooms has some similarities with the combining manifolds in the piping system. Both systems have multiple inlets or intake branches which converge into a single channel. In manifolds, intake branches can also be called as laterals while the main channel is called the header. Rooms connected to the ventilation shaft system has the similar function like laterals in manifolds, while the shaft itself has the similar function like the header. In manifolds, one of major design factor which affects the fluid flow is the diameter of the lateral and header pipe. In ventilation shaft system, the air flow can be affected by many factors like the room geometry, opening size, geometry and size of the ventilation shaft, etc. There are 3 types of openings in the ventilation shaft system. The first is the inlet opening located in the windward facade, the second is the internal opening which connects each room to the ventilation shaft and the last type is the outlet from the shaft to the outer environment.

One of the parameters affecting flow distribution in manifolds is lateral resistance [2]. A proper selection of lateral resistance can improve flow uniformity [3]. In multi zone cross ventilation, the room resistance is dependent on the internal porosity or size of the internal opening [4]. The ventilation shaft system can also be categorized as multi zone cross ventilation. Therefore, the resistance of each room in ventilation shaft system can be controlled by the size of its internal opening which in turn can also affect the flow distribution. This paper is aimed to investigate the effect of opening size configuration to the flow distribution in ventilation shaft system.

\section{EXPERIMENTAL}

\section{A. Method and Procedure}

The experiment is carried out using a Computational Fluid Dynamics (CFD) simulation. The 3D model required for the simulation is constructed based on a real 33 story 
apartment building located in Surabaya. The building is also assumed to be located in a suburban area due to the low density of tall building in the area around the object building. The apartment building has double loaded corridors with apartment units on each side of the corridors so that most of the apartment units have only one side connected to the outside. Therefore, to provide cross ventilation inside the apartment room, the proposed ventilation shaft is installed in the building model.

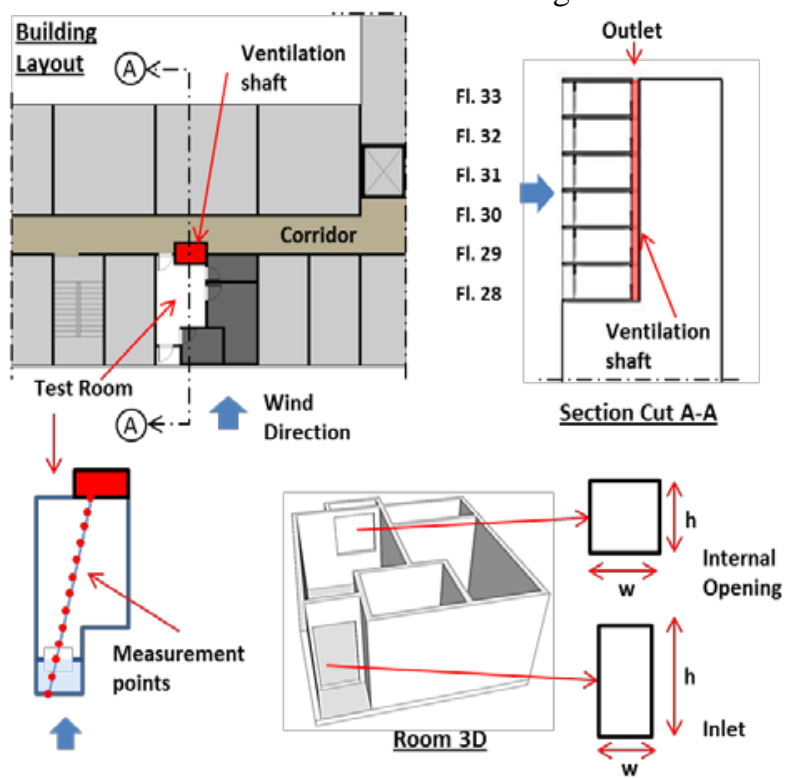

Figure 1. Details of model used in the experiment

The ventilation shaft system consists of 6 apartment units connected to a ventilation shaft vertically from floor 28th until floor 33rd. The room examined is the living room area of each apartment units which has 3 meters wide and 5 meters long, plus a $1,5 \mathrm{~m} \times 1 \mathrm{~m}$ area of the balcony. The ventilation shaft sized $2 \mathrm{~m} \times 1 \mathrm{~m}$ is located near the corridor (figure 1) and has an opening at the top which functions as the system's outlet. Each room has an opening to the windward side which functions as an inlet and also an internal opening in the back of the room which connects it to the shaft. Base case model has a uniform opening size, both the inlet and internal opening, in all rooms (see table 1). The wind direction is assumed to be coming straight from the front of the inlet or perpendicular to the building's windward facade.

TABLE 1.

OPENING SIZE CONFIGURATION FOR EACH MODEL (H X W IN METER).

\begin{tabular}{lllllll}
\hline \hline \multirow{2}{*}{ Floor } & \multicolumn{2}{c}{ Basecase } & \multicolumn{2}{c}{ B2 } & \multicolumn{2}{c}{ B3 } \\
\cline { 2 - 6 } & Inlet & Internal & Inlet & Internal & Inlet & Internal \\
\hline 33 & $2 \times 1$ & $1,4 \times 1,4$ & $2 \times 1$ & $0,5 \times 0,5$ & $2 \times 0,5$ & $0,5 \times 0,5$ \\
32 & $2 \times 1$ & $1,4 \times 1,4$ & $2 \times 1$ & $0,7 \times 0,7$ & $2 \times 0,6$ & $0,7 \times 0,7$ \\
31 & $2 \times 1$ & $1,4 \times 1,4$ & $2 \times 1$ & $0,9 \times 0,9$ & $2 \times 0,7$ & $0,9 \times 0,9$ \\
30 & $2 \times 1$ & $1,4 \times 1,4$ & $2 \times 1$ & $1,1 \times 1,1$ & $2 \times 0,8$ & $1,1 \times 1,1$ \\
29 & $2 \times 1$ & $1,4 \times 1,4$ & $2 \times 1$ & $1,3 \times 1,3$ & $2 \times 0,9$ & $1,3 \times 1,3$ \\
28 & $2 \times 1$ & $1,4 \times 1,4$ & $2 \times 1$ & $1,5 \times 1,5$ & $2 \times 1$ & $1,5 \times 1,5$ \\
\hline \hline
\end{tabular}

There are two treatments applied to the experiment. The first treatment is increasing the internal opening size from the upper floor to the lower floor and the second treatment uses the same method but also applied to both the inlet and internal openings. The first treatment is assigned to model B2 while the second treatment is assigned to model B3 (see table 1).

Every CFD simulation which includes outdoor wind environment requires a large area surrounding the model building or also called as the domain. There are some recommendations related to the ideal size of the domain for CFD simulation. [5] recommend that the upwind boundary should be at least 20B distance (B represents the width of the model building) from the edge of the model building, $5 \mathrm{H}$ distance for the upper boundary (H represents the height of the model building) and 30B distance for the downwind boundary. As for the simulation itself, the turbulence model used in the simulation is the RNG k-e model, following the recommendation.

Wind velocity required for the simulation can be obtained by averaging annual wind speed data from local meteorological office (BMKG Surabaya) and through a calculation using a power law or Eq.(1).

$$
V_{z}=V_{z G}\left(z / z_{G}\right)^{\alpha}
$$

Where $\mathrm{V}_{\mathrm{z}}$ is the wind velocity at certain height ( $\mathrm{z}$ ) and $\mathrm{V}_{\mathrm{zG}}$ is the wind velocity at the reference height $\left(\mathrm{z}_{\mathrm{G}}\right)$. Terrain roughness coefficient is represented by $\alpha$. Annual wind velocity average in Surabaya during $2010-2014$ is $3,34 \mathrm{~m} / \mathrm{s}$. Wind velocity data from BMKG is assumed to be observed at the height of $10 \mathrm{~m}$ in an open country area, while the ventilation shaft model is located at the height of $80-100 \mathrm{~m}$ in a suburban area. The two locations have different height and terrain roughness coefficient. Therefore, to obtain a proper wind velocity at the model location and height, a series of calculation using the Eq.(1) is required. Wind velocity obtained from the calculation is $3,82 \mathrm{~m} / \mathrm{s}$ which is then used for the CFD simulation.

\section{RESULTS AND DISCUSSION}

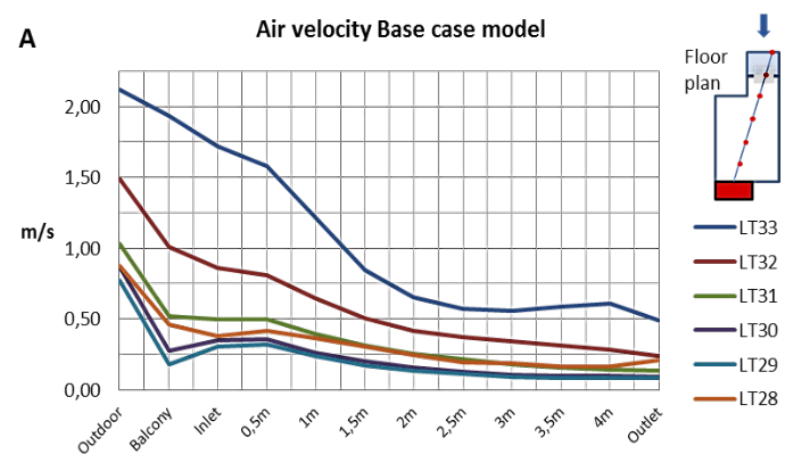




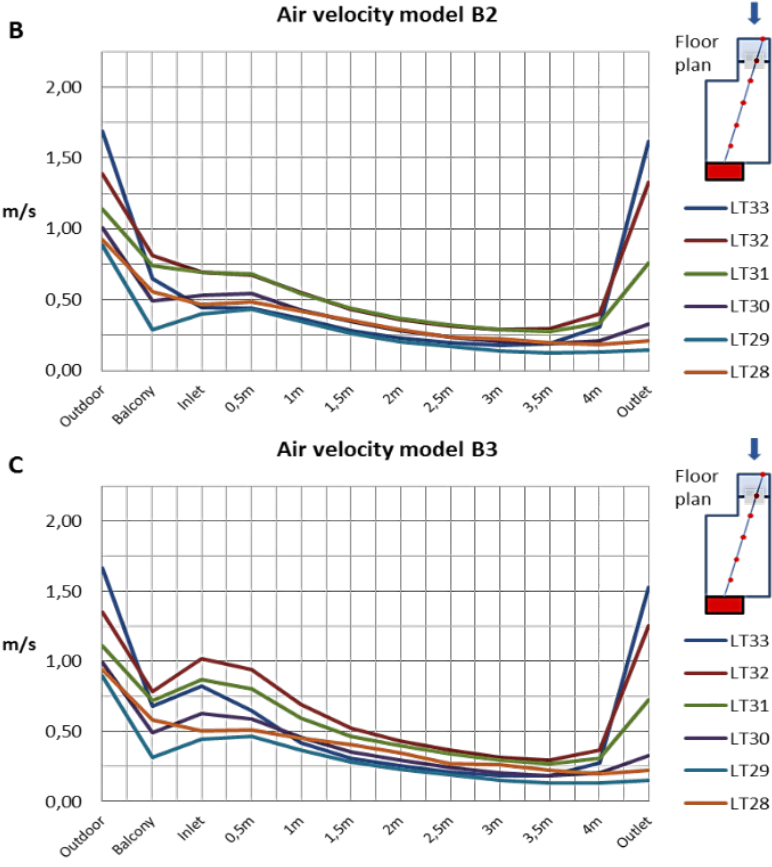

Figure 2. Air velocity on each floor for model Base case (A), B2 (B) and B3 (C)

Figure 2A shows that in base case model, there are large differences in air velocity between the upper floors, especially for the 33rd floor, and the lower floors. The air velocity at the inlet point on the 33rd floor is around 1,72 $\mathrm{m} / \mathrm{s}$ while on the 32nd floor the air velocity is much lower at $0,86 \mathrm{~m} / \mathrm{s}$ or about $50 \%$ less than at 33 rd floor. From the 31st floor to the 28th floor, air velocity at the inlet point is ranging between $0,50 \mathrm{~m} / \mathrm{s}$ to $0,31 \mathrm{~m} / \mathrm{s}$. The similar differences between the upper floors and the lower floors also happen at all measurement points. At the middle of the room (at depth $2,5 \mathrm{~m}$ from the inlet point), air velocity varies between $0,57 \mathrm{~m} / \mathrm{s}$ at the 33 rd floor to $0,11 \mathrm{~m} / \mathrm{s}$ at the 29th floor. Those differences indicate that the air flow in base case model is not distributed evenly on each floor.

TABLE 2.

AIR FLOW RATE $\left(\mathrm{M} / \mathrm{s}^{3}\right)$ ON EACH FLOOR FOR MODEL BASE CASE, B2 AND B3.

\begin{tabular}{cccccc}
\hline & BC & B2 & $\Delta \mathbf{Q}$ & B3 & $\Delta \mathbf{Q}$ \\
\hline FL33 & 2,72 & 0,72 & $-73 \%$ & 0,70 & $-74 \%$ \\
FL32 & 1,47 & 1,04 & $-29 \%$ & 0,99 & $-32 \%$ \\
FL31 & 0,86 & 1,01 & $17 \%$ & 0,97 & $13 \%$ \\
FL30 & 0,59 & 0,79 & $33 \%$ & 0,78 & $32 \%$ \\
FL29 & 0,47 & 0,61 & $28 \%$ & 0,63 & $33 \%$ \\
FL28 & 0,62 & 0,75 & $21 \%$ & 0,78 & $25 \%$ \\
\hline Total & 6,74 & 4,93 & $-27 \%$ & 4,86 & $-28 \%$ \\
\hline
\end{tabular}

Non-uniformity in flow distribution in the base case model is also confirmed by the measurement of air flow rate on each floor. Table 2 shows that the maximum air flow rate in base case model happens on the 33rd floor, which is the nearest floor to the outlet at the rooftop, and the minimum air flow rate happens on the 29th floor. The table also shows that the floor far from the outlet experiences lower air flow rate than the floor near from the outlet.

Figure 2B shows the air velocity on model B2 which has variation in the internal opening size. Air velocity at the inlet point varies between $0,70 \mathrm{~m} / \mathrm{s}$ to $0,40 \mathrm{~m} / \mathrm{s}$ while the air velocity at the middle of the room varies between $0,32 \mathrm{~m} / \mathrm{s}$ to $0,17 \mathrm{~m} / \mathrm{s}$, with the maximum air velocity at the 32nd and 31st floor and minimum air velocity at the 29th floor. The small difference in air velocity between each floor indicates that the variation in internal opening size can provide more uniform air flow distribution than the base case model.

Model B3 (as shown in figure 2C), which has variation in both inlet and internal opening, also experiences the similar result to model B2. In model B3, air velocity at the middle of the room varies between $0,36 \mathrm{~m} / \mathrm{s}$ at the $32 \mathrm{nd}$ floor to $0,13 \mathrm{~m} / \mathrm{s}$ at the 29th floor. The difference between model B2 and B3 lies in the air velocity at the inlet point. Model B3 generally experience higher air velocity at the inlet point due to variation in the size of the inlet opening.

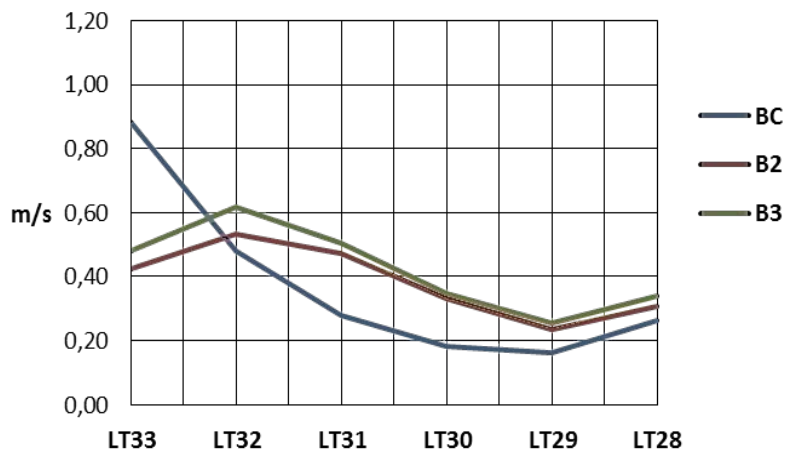

Figure 3. Air velocity average on each floor for model Base case, B2 and B3

Figure 3 shows the comparison of air velocity average on each floor between base case, B2, and B3 model. According to Figure 3, internal opening size variation on model B2 can increase average air velocity at the 32nd floor to 28th floor by $12 \%$ to $80 \%$ but also reduced air velocity at the 33rd floor by $52 \%$. Similar variation in the inlet and internal opening size on model B3 doesn't produce a much different effect. Average air velocity at floor 33rd and 32nd on model B3 are slightly better than model B2 due to the small inlet size which causes air velocity increase around the inlet.

Measurement of air flow rate on each floor also indicates that the variation in internal opening size can produce more uniform air flow distribution. According to Table 2, model B2 and B3 experience increased air flow rate at the lower floors (floor 31st to 28th) but also reduced air flow rate at the upper floors (floor 33rd and 32nd) if compared to the base case model. Despite the effect in delivering more uniform air velocity distribution, variation in the inlet and internal opening can also reduce the total amount of air flow rate of the ventilation shaft system. Compared to the base case model, both the B2 and B3 model experience lower total air flow rate, respectively by $27 \%$ and $28 \%$ lower than the base case model. 
According to [6], in a combining manifold, the flows into lateral far from the outlet experience more junction losses than those close to the outlet. If all the lateral has the same diameter, the lateral discharge will decrease from the lateral near the outlet to the lateral far from the outlet. The similar problem also occurs in the base case model which has a uniform size of the inlet and internal opening in all rooms. It indicates that non-uniformity of air flow distribution in the base case model can also be caused by the same reason which causes non-uniformity of flow distribution in the combining manifold mentioned above.

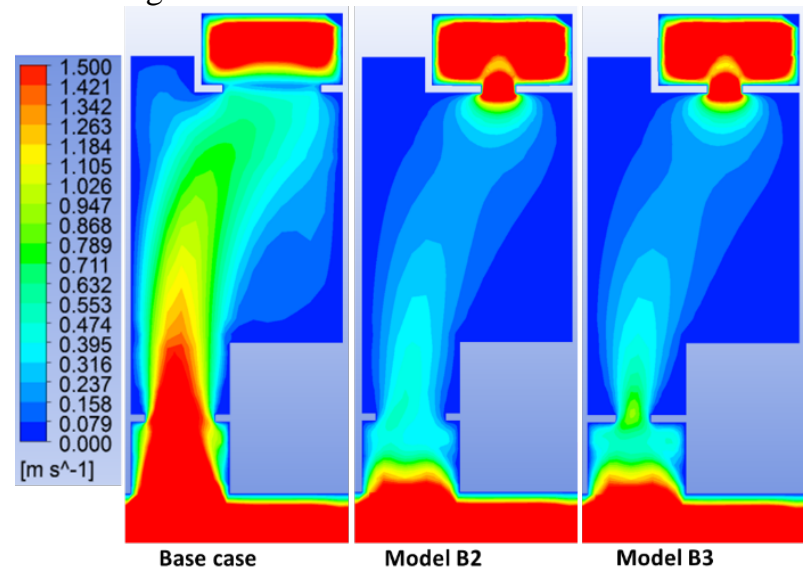

Figure 4. Air velocity contour at $1 \mathrm{~m}$ height above the 33rd floor for model Base case, B2 and B3

Variation in the opening size is an attempt to increase the uniformity of air flow distribution in ventilation shaft system by regulating the resistance of each floor connected to the ventilation shaft. The room near from the outlet has smaller internal opening than the room far from the outlet which also means that the room near from the outlet experiences more resistance than the room far from the outlet. Such configuration can force the air to flow through the room with less resistance so that there are more air flows through the lower floor. Results from the simulation of model B2 and B3 prove that the variation in opening size, especially the internal opening, can increase air flow distribution on the 31st floor to the 28th floor. Additional variation in the inlet opening doesn't produce much effect, except the slight increase in air velocity at the inlet of some rooms (see figure 4). The air flow will experience an acceleration if it is forced to pass through a small opening, which is also called the venturi effect. This kind of acceleration occurs near the internal opening on the upper floors of model B2 and also near both the inlet and internal opening on the upper floors of model B3.

\section{CONCLUSION}

Ventilation shaft system connected to multiple floors will experience a non-uniform air flow distribution if it has a uniform opening size in all rooms. Variation in internal opening size, by increasing it from the upper floor to the lower floor, can increase the average air velocity distribution at the lower floors by $12 \%$ to $80 \%$ but also decreases average air velocity at the top floor by $52 \%$. Variation in both inlet and internal openings also produces a very similar result compared to variation in internal opening only. However, variation in opening size can also increase the system's overall resistance which results in the decrease of air flow rate by $27 \%$ to $28 \%$.

\section{REFERENCES}

[1] P. Prajongsan and S. Sharples, "Enhancing natural ventilation, thermal comfort and energy savings in high-rise residential buildings in Bangkok through the use of ventilation shafts," Build. Environ., vol. 50, pp. 104-113, Apr. 2012.

[2] R. A. Bajura, “A Model for Flow Distribution in Manifolds," J. Eng. Power, vol. 93, no. 1, p. 7, Jan. 1971.

[3] J. Wang, "Theory of flow distribution in manifolds," Chem. Eng. J., vol. 168, no. 3, pp. 1331-1345, Apr. 2011.

[4] C.-R. Chu and Y.-W. Wang, "The loss factors of building openings for wind-driven ventilation," Build. Environ., vol. 45, no. 10, pp. 2273-2279, Oct. 2010.

[5] J. Revuz, D. M. Hargreaves, and J. S. Owen, "On the domain size for the steady-state CFD modelling of a tall building," Wind Struct., vol. 15, no. 4, pp. 313-329, Jul. 2012.

[6] W.-F. Chen and J. Y. R. Liew, The civil engineering handbook. CRC Press, 2003. 